\title{
A luciferase based viability assay for ATP detection in 384-well format for high throughput whole cell screening of Trypanosoma brucei brucei bloodstream form strain 427 \\ Melissa L Sykes and Vicky M Avery*
}

Address: Eskitis Institute for Cell and Molecular Therapies, Griffith University, Eskitis Building N27, Brisbane Innovation Park, Don Young Road, Nathan, Queensland, Australia

Email: Melissa L Sykes - m.sykes@griffith.edu.au; Vicky M Avery* - v.avery@griffith.edu.au

* Corresponding author

Published: 12 November 2009

Parasites \& Vectors 2009, 2:54 doi:10.1186/1756-3305-2-54
Received: 9 September 2009

Accepted: 12 November 2009

This article is available from: http://www.parasitesandvectors.com/content/2/1/54

(C) 2009 Sykes and Avery; licensee BioMed Central Ltd.

This is an Open Access article distributed under the terms of the Creative Commons Attribution License (http://creativecommons.org/licenses/by/2.0), which permits unrestricted use, distribution, and reproduction in any medium, provided the original work is properly cited.

\begin{abstract}
Background: Human African Trypanosomiasis (HAT) is caused by two trypanosome species, Trypanosoma brucei rhodesiense and Trypanosoma brucei gambiense. Current drugs available for the treatment of HAT have significant issues related to toxicity, administration regimes with limited effectiveness across species and disease stages, thus there is a considerable need to find alternative drugs. A well recognised approach to identify new drug candidates is high throughput screening (HTS) of large compound library collections.

Results: We describe here the development of a luciferase based viability assay in 384-well plate format suitable for HTS of T.b.brucei. The parameters that were explored to determine the final HTS assay conditions are described in detail and include DMSO tolerability, Z', diluents and cell inoculum density. Reference compound activities were determined for diminazene, staurosporine and pentamidine and compared to previously published $\mathrm{IC}_{50}$ data obtained. The assay has a comparable sensitivity to reference drugs and is more cost effective than the 96 -well format currently reported for T.b.brucei.

Conclusion: Due to the reproducibility and sensitivity of this assay it is recommended for potential HTS application. As it is commercially available this assay can also be utilised in many laboratories for both large and small scale screening.
\end{abstract}

\section{Background}

Sleeping sickness, or Human African Tropanosomiasis (HAT), is a disease caused by two species of trypanosomes, Trypanosoma brucei rhodesiense and Trypanosoma brucei gambiense. The disease occurs in 36 countries in sub Saharan Africa. In 2006, there was an estimated cumulative rate of 50000-70000 cases worldwide [1]. The disease occurs in two stages, the first whereby trypanosomes multiply in the blood and lymphatic system, and includes symptoms such as headaches, fever, joints pain and itching. In the second stage, trypanosomes cross the blood brain barrier to the central nervous system and neurological symptoms often become apparent. Without treatment of the infection, the disease becomes fatal.

HAT chemotherapy relies upon a limited number of drugs, which are not effective against all stages or trypanosome species, have associated side effects or impractical 
administration regimes. Two of these drugs, suramin and pentamidine, are only effective against the first stage of disease, and are selective against T.b.rhodesiense and T.b.gambiense, respectively. Melarsoprol, which is effective against the second stage of the disease, causes encephalopathy in $5-10 \%$ of treated patients [2]. Eflornithine, also a second stage specific drug, is less toxic however is not effective against T.b.rhodesiense [3]. Suramin, pentamidine, melarsoprol and eflornithine all require intravenous injection for treatment which is not practical considering the poor medical facilities in most of the disease endemic areas. There also has been an increase in melarsoprolrefractory sleeping sickness cases which suggests possible emergence of melarsoprol-resistant trypanosomes $[4,5]$.

The strong need for new, less toxic HAT drugs, which are particularly effective against the second stage of the disease has resulted in a variety of approaches to identify new treatments which are not uncommon approaches within anti-parasitic drug discovery. These options include combinations of existing HAT drugs (such as eflornithine and melarsoprol; [6]), new indications for existing drugs for unrelated disorders and improvements to a number of known drugs and compound classes [7]. High throughput screening (HTS) of whole parasites against large compound libraries has also been undertaken in the search for new therapeutic candidates [8]. The application of HTS in drug discovery has been explored in neglected disease area for some time, as this approach has the potential of identifying new drugs with novel modes of action. Thus, HTS remains an important consideration for HAT drug discovery programmes.

HTS of specific targets have been reported in the literature for T.brucei species. Assays in 384-well format have been developed to detect trypanothione reductase activity $[9,10]$, however these do not involve the whole parasite. There have been few reports in the literature for HTS methods for whole cell screening for HAT. A viability assay which has been extensively reported in the literature for all T. brucei species and which utilises the dye Alamar Blue $^{\mathrm{TM}}$ has been used a 96-well format by a number of authors [11-14]. We have recently developed a 384-well Alamar Blue assay for T.b.brucei whole cell viability estimation [15]. As an alternative to the Alamar Blue assay, a luciferase viability assay has recently been published for T.b.brucei whole cell screening in a 96-well format [16]. This paper reports the use of a bioluminescent ATP detection assay for HTS for a screening set of 2000 compounds. The same author has also reported the use of this assay for a smaller study of protease inhibitors against T.b.brucei [17]. It would be of benefit, in terms of time and cost considerations, to develop such a viability assay for T.b.brucei whole cells in a 384-well format for HTS. T.b.brucei has been routinely used in screening for initial identification of anti-trypanosomal compounds for potential anti-HAT drugs [7]. T.b.brucei causes trypanosomiasis in cattle [18] and is non-infective to humans [19]. For identification of lead compounds following HTS, actives are subsequently screened against human infective HAT strains for confirmation of activity.

The luciferase based viability assay described here utilizes firefly luciferase to detect intracellular ATP levels in viable cells. The reaction involves the mono-oxygenation of luciferin catalysed by luciferase in the presence of ATP, magnesium and molecular oxygen, the reaction yielding a luminescent signal. This assay has previously been used for determining viability of various cell types, and numerous kits are commercially available from a number of different suppliers. These kits, such as CellTiter- Glo ${ }^{\varpi}$, are quick and efficient, with only 10 minutes required for signal development. In comparison, the Alamar Blue assay has a 6-24 hour incubation period for T.b.brucei cell viability assays reported in a 96-well format [5,11-13]. Although many published 96 well assay formats employ Alamar Blue development at $5 \% \mathrm{CO}_{2}$ and $37^{\circ} \mathrm{C}$ inclusive of a total assay incubation time, we recently found these conditions to reduce the growth of T.b.brucei during 384 well plate assay optimisation [15]. We used a 24 hour incubation at room temperature with Alamar Blue following 72 hours of cell growth, for further signal development, as cell growth was reduced under these conditions (40 hours doubling time). We also found assay sensitivity was not significantly affected by this extra incubation. In this case, turn around would be faster for the luciferase assay as the development of signal is more rapid.

Here we report the development of a 384-well whole cell luciferase based viability assay for the detection of the viability of T.b.brucei whole cells. This assay was developed to HTS standards by incorporating the following statistical parameters: $Z^{\prime}$ factor $\left(Z^{\prime}\right)$, \% coefficient of variation (\% $\mathrm{CV}$ ) and the signal to background assay window to reflect reproducibility. The $Z^{\prime}$ is a measurement of the reproducibility of an assay as described by Zhang and others [20]. This value is an indicator of the quality of an assay by analysing the variation of samples of positive and negative controls (no test compounds), and application of the use of this parameter to define the reproducibility of assays has been reported extensively [21]. An ideal assay would have a $Z^{\prime}$ of 1 . A Z' of 0 would define an assay that could not be applied to screening due to poor reproducibility [22] and therefore would require further optimisation. The \% CV denotes variation of an assay signal relative to the mean. It can be applied to one control variable rather than requiring both negative and positive controls. Generally, a Z' of greater than 0.5 with a \% CV of less than 10 is acceptable for HTS. A \% CV of greater than $17 \%$ indicates that the $Z^{\prime}$ will not reach 0.5 [23] and the closer to 0 the 
$\% \mathrm{CV}$ is, the more reproducible, and therefore suitable an assay will be for HTS.

Optimisation of the established assay into 384-well format incorporated analysis of assay variables such as cell concentration, sensitivity to compound solvent, compound dilution medium and the $\mathrm{IC}_{50}$ values of a panel of reference compounds reported in the literature. The reference compounds used in this study consisted of the known drugs, pentamidine, and diminazene and a general kinase inhibitor, staurosporine. Diminazene and pentamidine have reported $\mathrm{IC}_{50}$ values from various publications which employ the Alamar Blue reagent for viability detection [11-13]. Diminazene is a registered veterinary drug used against T.b.brucei. Staurosporine has reported activity against T.b.brucei [16], as well as other trypanosome species, such as Trypanosoma cruzi [24] and Leishmania species [25].

The luciferase based ATP detection assay described here satisfies HTS assay criteria with a Z' of greater than 0.5 . The assay is comparable with respect to known reference compound activities as those reported in the literature for the Alamar Blue assay in format [11-13], as well as the reported luciferase based assay in a 96-well format [16]. The parameters that were explored and optimised to provide a HTS assay in 384-well format are discussed in detail.

\section{Methods}

\section{Parasites and in vitro culture}

T.b.brucei bloodstream form strain 427 (BS427) was kindly supplied by Dr Achim Schnaufer, (Institute of Cell Biology, University of Edinburgh, UK) whilst at the Seattle Biomedical Research Institute (Seattle, WA, USA). The trypanosomes were maintained in log phase growth in 25 $\mathrm{cm}^{2}$ tissue culture flasks (vented, $25 \mathrm{~cm}^{2}$ Corning, Lowell, MA, USA) by sub culturing at either 24 or 48 hour intervals. Cells were grown in complete HMI-9 medium [26], supplemented with $10 \%$ FCS and $100 \mathrm{IU} / \mathrm{mL}$ penicillin/ streptomycin (Invitrogen, Carlsbad, CA, USA). Cells were grown by incubating in conditions of $5 \% \mathrm{CO}_{2}$ and $37^{\circ} \mathrm{C}$ in a humidified atmosphere.

\section{Statistical Analysis of Samples}

For matrices of concentrations of cells and reagent, sample sets consisted of 8 wells. For initial set up experiments, combinations of conditions were analysed by comparing the signal to background ratio (cell concentrations versus addition of the same volume of HMI-9 medium alone).

For larger well samples, over one third of a 384-well plate, the signal to background ratio of control plates (1) and Z' (3) were calculated as per Zhang and colleagues [20].
Whereby

(1) $\mathrm{S} / \mathrm{B}=$ mean signal/mean background

(2) $\mathrm{SD}=$ standard deviation

(3) $Z^{\prime}$ factor $=1-\left[\left(3 * S_{A}+3 S_{B}\right) /(\right.$ meanA-meanB $\left.)\right]$

where $\mathrm{A}=$ mean end point signal of each assay (cell growth detected in wells containing T.b.brucei in HMI-9 medium in a 384-well plate after 72 hours growth); $\mathrm{B}=$ background signal, HMI-9 media incubated for 72 hours with no cell addition, or with addition of $2.8 \mu \mathrm{M}$ final pentamidine concentration.

For all reference drug compound $\mathrm{IC}_{50}$ estimations, activity at each compound dose was averaged from triplicate experiments and expressed $\pm \mathrm{SD}$ in $\mathrm{nM}$.

\section{Final optimised HTS assay conditions}

The final optimised assay protocol, suitable for HTS, was established through variation of the conditions used as outlined. Unless stated otherwise, the basic HTS method was used. All additions of reagents and cells were made with a Multidrop ${ }^{\mathrm{TM}}$ liquid handler (Thermo Scientific, Newington, $\mathrm{NH}$ ) under sterile conditions. Fifty-five $\mu \mathrm{L}$ of 500 cells/mL of T.b.brucei in HMI-9 medium were added to a white solid lidded 384-well plate (PerkinElmer, Waltham, MA, USA). Cells were incubated for 24 hours at $37^{\circ} \mathrm{C}$ with $5 \% \mathrm{CO}_{2}$ in humidified conditions before addition of $5 \mu \mathrm{L}$ of compound prepared in $100 \% \mathrm{DMSO}$, or $100 \%$ DMSO only for control wells. Compounds and/or DMSO were pre-diluted 1:40 in HMI-9 medium using a MiniTrak $^{\mathrm{TM}}$ robotic liquid handler (PerkinElmer, Waltham, MA, USA). Five $\mu \mathrm{L}$ of diluted sample was added to the each well using the MiniTrak, giving a final DMSO concentration of $0.208 \%$. Cells were incubated for a further 48 hours at $37^{\circ} \mathrm{C}$, resulting in a final incubation time of 72 hours, of which trypanosomes were exposed to test compounds for 48 hours. Fifteen $\mu \mathrm{L}$ of a luciferase based reagent, CellTiter-Glo (Promega Inc, Madison, WI, USA) was then added for detection of intracellular ATP. The plate was shaken for 2 minutes to facilitate cell lysis and the release of intracellular ATP, and then incubated for a further 10 minutes at room temperature. The plate was read on a TriLux plate reader (PerkinElmer, Waltham, MA, USA), utilising a luminescence protocol.

\section{Luciferase assay and detection of exogenous ATP}

To establish the limits of detection for ATP, varying concentrations of ATP from $8 \mathrm{nM}$ to $400 \mu \mathrm{M}$ (in HMI-9 medium) were added to a 384-well plate (as outlined in final assay conditions). Detection was performed by addition of $15 \mu \mathrm{L}$ of the luciferase based reagent, as a mid- 
range volume trialed for this assay (volumes of trypanosomes were varied from $25 \mu \mathrm{L}$ to $10 \mu \mathrm{L}$ for initial growth experiments). Fifty-five $\mu \mathrm{L}$ of each concentration of the ATP solution were added to four 384-wells, with detection as outlined in final assay conditions.

\section{Doubling time of T.b.brucei in flask culture}

The doubling time for T.b.brucei was originally calculated to be 6.8 hours in a flask culture [15]. To determine if this was constant over multiple T.b.brucei cell splits, the doubling time was calculated at 24 hour intervals by maintaining the final concentration of cells at $1 \times 10^{6} \mathrm{cells} / \mathrm{mL}$ and the cells were estimated to be in log phase over this time period. The calculation was based upon manipulation of the doubling time equation, using a known doubling time of 6.8 hours.

To determine if the doubling time was stable at 6.8 hours, the prepared culture dilution was signified as quantity $\left(\mathrm{q}_{1}\right)$ at time $\left(\mathrm{t}_{1}\right)$ and the resultant density following 24 hours incubation was quantity $\left(\mathrm{q}_{2}\right)$ at time $\left(\mathrm{t}_{2}\right)$ as per the doubling time equation:

$$
\mathrm{T}_{\mathrm{d}}=\left(\mathrm{t}_{2}-\mathrm{t}_{1}\right) * \frac{\log (2)}{\log \left(\mathrm{q}_{2} / \mathrm{q}_{1}\right)}
$$

Where $\mathrm{T}_{\mathrm{d}}=$ doubling time.

To compare the doubling time of a flask culture to that of a culture in a well, the same cell density of trypanosomes in $55 \mu \mathrm{L}$ was added to wells of a white solid lidded 384well plate as to a flask culture, to gain an estimated $1 \times 10^{6}$ cells/mL following 24 hours growth. Three wells from the plate and 3 replicates from the flask were counted and compared for doubling time.

\section{Detection of trypanosomes inoculated from flask grown cultures in to a 384-well plate}

Fifty-five $\mu \mathrm{L}$ of trypanosomes at $3 \times 10^{6} \mathrm{cells} / \mathrm{mL}$ were diluted to 1 and $2 \times 10^{6} \mathrm{cells} / \mathrm{mL}$, respectively and transferred directly to a 384-well plate. Twenty-five, 20, 15 and $10 \mu \mathrm{L}$ of CellTiter-Glo reagent were added to the replicate volumes of trypanosomes. Detection was as described in the final assay conditions, with the only variation being the reagent volume. The \% CV and signal to background ratio of well samples was used to define ideal reagent volumes to employ for further assay set up for growth in 384well plates.

To further estimate the limitations of detection for the ATP detection assay with respect to cell concentration, 55 $\mu \mathrm{L}$ of varying densities of trypanosomes in a larger range of doses from 976 cells/mL to $3 \times 10^{6}$ cells/mL in HMI-9 medium were added to a 384-well plate. Cultures diluted from were at $3 \times 10^{6}$ cells $/ \mathrm{mL}$ (for above $1 \times 10^{6}$ cells $/ \mathrm{mL}$ density); and $1 \times 10^{6}$ cells/mL. Detection was undertaken as described in the final assay conditions.

\section{Growth and detection of trypanosomes in 384-well plate}

Plates were inoculated at a variety of cell concentrations from 0 to 4000 trypanosomes/mL in $55 \mu \mathrm{L}$ of HMI-9 medium and incubated at $37^{\circ} \mathrm{C}$ in $5 \% \mathrm{CO}_{2}$ for 72 hours. Three wells were harvested and counted with a haemocytometer at each 24 hour period to estimate growth. CellTiter-Glo reagent was added to each cell concentration at each time interval at either 10 or $15 \mu \mathrm{L}$ additions for comparison. The signal to background ratio and \% CV of sample wells for each assay and trypanosome/reagent volume combinations were estimated. To obtain statistically relevant data each treatment was performed over 8 wells of replicates.

\section{Reference Compound $I C_{50}$ determination}

The $\mathrm{IC}_{50}$ value of each reference compound was calculated by plotting \% inhibition (100\% inhibition was equal to $2.8 \mu \mathrm{M}$ final pentamidine) against log [reference compound] in the software package PRISM 4 graph pad (denoted $\mathrm{IC}_{50}$ by PRISM). The $\mathrm{IC}_{50}$ value was the concentration of compound that was estimated to lead to $50 \%$ of growth; with the minimum of $0 \%$ growth (cells co-incubated with $2.8 \mu \mathrm{M}$ pentamidine) and 100\% growth (no compound addition). Each dose was screened in triplicate.

\section{Optimisation of DMSO concentration and compound dilution medium}

Fifty-five $\mu \mathrm{L}$ of T.b.brucei at a density of 500 cells/mL was inoculated into a 384-well plate and incubated for 24 hours. Five $\mu \mathrm{L}$ of varying concentrations of DMSO diluted in HMI-9 medium with no FCS were added to each plate. Plates were incubated for a further 48 hours and the HTS protocol, as outlined in the final assay conditions, was undertaken. One quarter of a 384-well plate was used to calculate the $\mathrm{Z}$ ' for each treatment.

The final assay conditions for the HTS protocol as outlined in the methods were used to estimate the $\mathrm{IC}_{50}$ values of the reference compounds pentamidine, diminazene and staurosporine in three independent experiments. The final optimised conditions included an inoculum of 500 cells/mL, $15 \mu \mathrm{L}$ of CellTiter-Glo and a final DMSO concentration of $0.208 \%$, with no FCS in the dilution medium.

For optimisation of compound dilution medium, additions of HMI-9 medium, water, HMI-9 medium without FCS supplement and PBS were compared with respect to assay sensitivity to reference compounds. The final assay conditions used in this experiment were varied only by the diluent used. 


\section{Results}

Luciferase assay signal from exogenous ATP

The luciferase assay could detect ATP concentrations with a signal window (to background of HMI-9 medium with no ATP addition) down to the lowest dose tested at a final concentration of $8 \mathrm{nM}$, with a $15 \mu \mathrm{L}$ addition of detection reagent to $55 \mu \mathrm{L}$ of ATP solution in HMI-9 medium. The signal window was $24.5 \pm 2.6$ times that of media with no ATP, with a mean signal of $90.4 \pm 9.4$ CPM for $8 \mathrm{nM}$ of ATP. The highest concentration that could be detected within the linear range was $40 \mu \mathrm{M}$ ATP with a signal window estimated to be $2.9 \times 10^{4} \pm 1439$ times with a luminescent signal of $9.1 \times 10^{4} \pm 3504 \mathrm{CPM}$ (Figure $1 \mathrm{~A}$ ). There was a linear relationship to this point, with an $\mathrm{r}^{2}$ estimated at 0.96 (Figure $1 \mathrm{~B}$ ). The signal had begun to plateau at 400 $\mu \mathrm{M}$, with a mean value of $1.70 \times 10^{5} \pm 5600 \mathrm{CPM}$ (Figure $1 \mathrm{~A})$.

\section{Doubling time of T.b.brucei in flask culture}

The doubling time in a flask of T.b.brucei cultures of cells did not vary from the estimate previously made at 6.8 hours. We did not find a significant variation in a flask versus plate culture doubling time with a ratio of $0.97 \pm$ 0.05 over 3 replicate independent experiments.

\section{Detection of trypanosomes from a flask grown culture transferred directly to a 384-well plate}

A decrease in the cell density of trypanosomes from 3 to 1 $\times 10^{6}$ cells $/ \mathrm{mL}$, for all of the luciferase reagent volumes tested, resulted in an increase in the mean CPM, with the highest counts seen at $1 \times 10^{6} \mathrm{cells} / \mathrm{mL}$ (Figure 2 ). Detection with $25 \mu \mathrm{L}$ of luciferase reagent resulted in the great- est signal window across treatments; with a maximum of a 657 times window of cells to HMI-9 medium with no cell addition, and a \% CV of $8.8 \%$. A reduction to $20 \mu \mathrm{L}$ reduced the $\% \mathrm{CV}$ to $5.2 \%$ and to $15 \mu \mathrm{L}$ the $\% \mathrm{CV}$ was $3.7 \%$. The signal window for $15 \mathrm{uL}$ of reagent was 646 times. In consideration of cell growth likely resulting in higher well to well variation compared with direct inoculation in the plate, the lowest \% CV with the highest signal window at $1 \times 10^{6}$ cells/mL was used as a criteria for the concentration and volume used for further investigation, which was with addition of $15 \mu \mathrm{L}$ of the CellTiter-Glo reagent.

Figure 3A shows that the trend of a reduction in CPM seen in initial experiments from densities of $1-3 \times 10^{6} \mathrm{cells} / \mathrm{mL}$ was replicated with a $15 \mu \mathrm{L}$ detection volume of luciferase and $55 \mu \mathrm{L}$ of trypanosomes, with intermediate doses. Cell concentrations were at 3 to $0.75 \times 10^{6}$ cells $/ \mathrm{mL}$ then in $0.5 \times$ increments from $0.5 \times 10^{6}$ cells $/ \mathrm{mL}$ to 488 cells $/ \mathrm{mL}$. Detection of $3 \times 10^{6}$ cells $/ \mathrm{mL}$ of trypanosomes resulted in a mean CPM of $1.1 \times 10^{4} \pm 1046$, with a CV of $9.6 \%$. A reduction of the cell density to $1 \times 10^{6}$ cells $/ \mathrm{mL}$ resulted in an increased signal, with a reduced $\% \mathrm{CV}$, to $7.5 \%$. Detection of $2 \times 10^{6}$ cells/mL resulted in a mean CPM of $1.2 \times$ $10^{4} \pm 911$ and $\mathrm{CV}$ of $8.9 \%$; however the signal had plateaued from $1 \times 10^{6}$ cells $/ \mathrm{mL}$. The greatest signal window closest to the linear end of detection was therefore observed to be at a $1 \times 10^{6}$ cells/mL density (Figure 3B).

Growth and detection of trypanosomes in 384-well plate Initial studies indicated that $1 \times 10^{6}$ cells $/ \mathrm{mL}$, with $15 \mu \mathrm{L}$ of detectant, provided an optimum signal to background

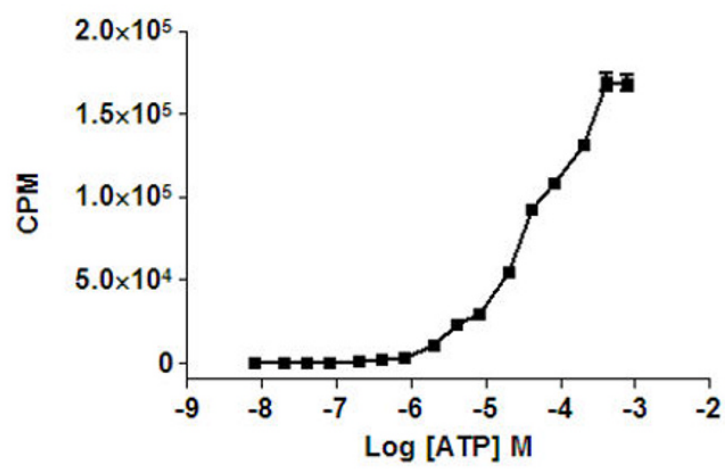

A

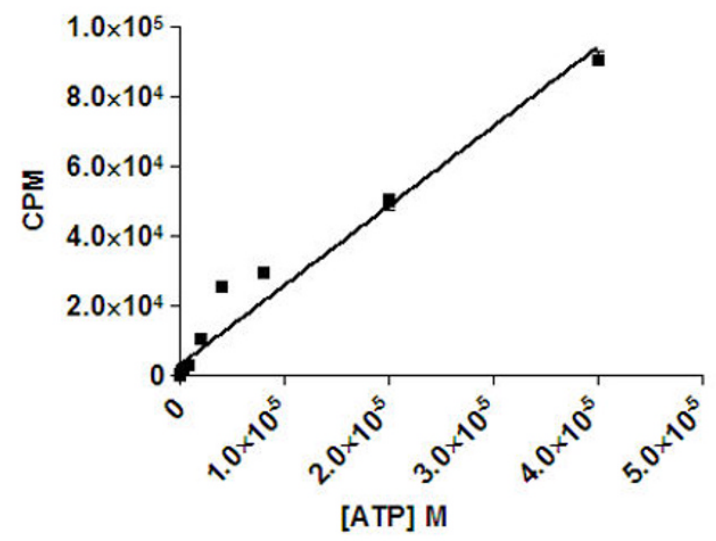

B

\section{Figure I}

Detection of exogenous ATP with the luciferase assay. (A) Fifty-five $\mu$ L of ATP in HMI- 9 medium detected by I $5 \mu L$ of CellTiter-Glo reagent over a dose range resulting in a plateau of the signal at $400 \mu \mathrm{M}$. (B) Representation of a linear range of ATP detection with CellTiter-Glo over varying concentrations of ATP. Linearity was approximately $40 \mu M$ before the signal plateau. Each concentration was screened in triplicate. The experiment was repeated twice. 


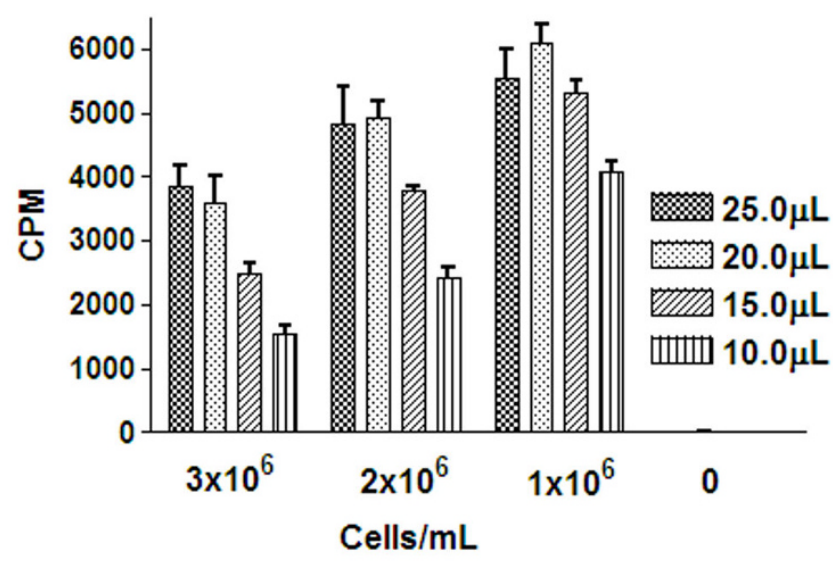

Figure 2

Combination of cell concentrations of T.b.brucei and reagent volumes for signal detection when a 384-well plate inoculated directly from flask culture dilutions and detected by the luciferase ATP detection assay. Fifty-five $\mu \mathrm{L}$ of T.b.brucei cell densities ranging from I-3 $310^{6}$ cells $/ \mathrm{mL}$ were transferred from a flask culture in to a 384 well plate and detected with CellTiter-Glo. Twenty-five, 20, 15 and $10 \mu \mathrm{L}$ volumes of CellTiter-Glo were compared for signal detection and reproducibility.

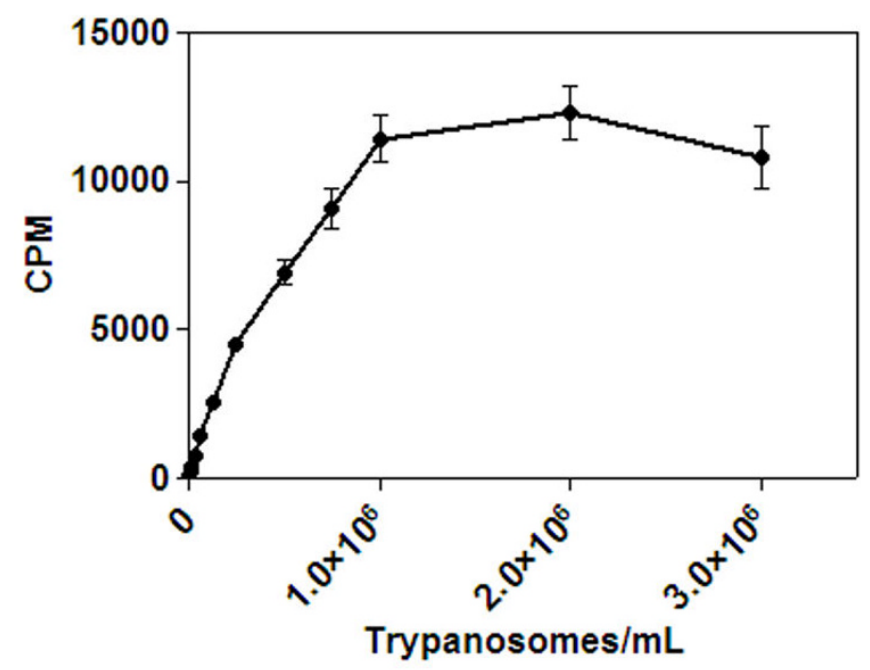

A ratio for the assay. To determine the most suitable inoculum density to obtain an optimal parasite growth in a 384-well plate, whilst taking into consideration assay performance over a 72 hour period, the cell number used as the inoculum per well was titrated as follows $0,62,125$, 250, 500, 1000, 1500 and 2000 cells/mL. Growth by cell count estimations of cells following 72 hours incubation are shown in Figure 4 . Approximately $3 \times 10^{6} \mathrm{cells} / \mathrm{mL}$ was the maximum attainable number using an inoculum of 2000 cells $/ \mathrm{mL}$. An increase in inoculum to 3000 cells $/ \mathrm{mL}$ resulted in a decrease in cell number. The signals obtained for differing cell concentrations, with 10 and $15 \mu \mathrm{L}$ of luciferase reagent are shown in Figure 5. The greatest assay signal to background window was obtained when $15 \mu \mathrm{L}$ of the luciferase reagent was used for detection of trypanosomes. With a $10 \mu \mathrm{L}$ detection reagent addition across cell concentrations a reduced signal was observed. The lowest $\% \mathrm{CV}$ and greatest window combination was observed using an inoculum of 500 cells $/ \mathrm{mL}$. This inoculum produced $1.7 \times 10^{6}$ cells $/ \mathrm{mL}$ (Figure 4 ). A slight decrease in CPM was seen from 1000 cells $/ \mathrm{mL}$ inoculum (a final density of $2.7 \times 10^{6}$ cells $/ \mathrm{mL}$ ) and a plateau of the signal from 2000 cells/mL inoculum (a final cell density of over $3 \times$ $10^{6}$ cells $/ \mathrm{mL}$ ).

Figure 3

T.b.brucei cells directly transferred from a flask culture to a 384 well plate and ATP detected with I5 $\mu$ L luciferase based reagent. (A) Cell concentrations of T.b.brucei and detection by the luciferase based assay of $55 \mu \mathrm{L}$ per well of over a dose range to $3 \times 10^{6}$ cells $/ \mathrm{mL}$ with cells transferred directly from dilutions made from flask grown cultures. I5 $\mu \mathrm{L}$ of luciferase reagent was added for detection. The mean CPM was estimated over 4 replicates from two separate experiments.

(B) There was a linear relationship between cell number and trypanosomes to $1 \times 10^{6}$ cells $/ \mathrm{mL}\left(r_{2}=0.99\right)$. 


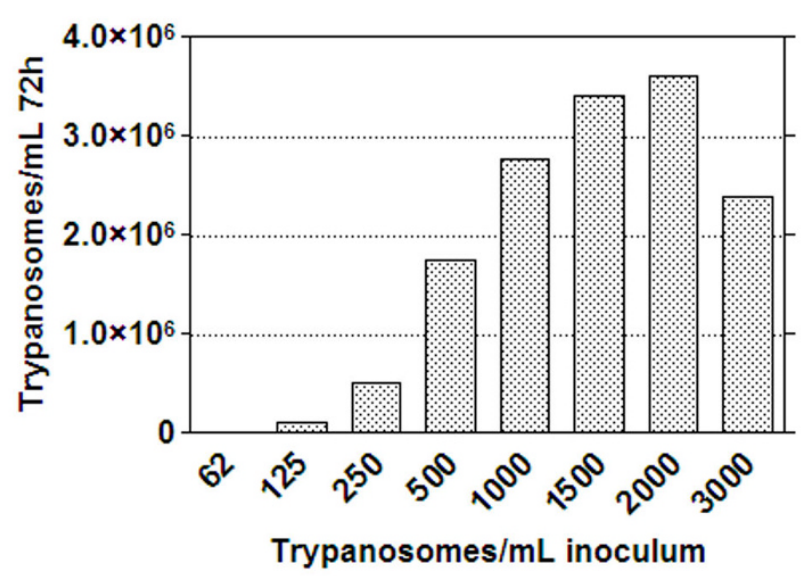

Figure 4

Cell counts of T.b.brucei following growth at 72 hours in a 384-well plate. Varying inocula of trypanosomes were grown in $55 \mu \mathrm{L}$ of HMI-9 media and harvested for counting after 72 hours growth.

\section{Reference compound $I C_{50}$ estimation and cell inoculum} Reference compounds (outlined in methods) were screened over a dose range of cell inoculum densities of 2000, 1500, 1000, 500 and 250 cells/mL and estimations of reference compound $\mathrm{IC}_{50}$ values were initially undertaken by the serial dilution of compound stocks in $100 \%$ DMSO in to HMI-9 medium (Table 1). A $5 \mu \mathrm{L}$ volume of these dilutions was added to each well, following an initial 24 hours incubation of cells in the absence of the compound, which was to determine cell growth in the plate, and to allow the equilibration of growth of the parasite in the plate. The DMSO concentration used was at a final concentration of $0.27 \%$ at the top dose in the assay for diminazene, $0.08 \%$ for pentamidine and $0.20 \%$ for staurosporine, DMSO is less likely to significantly affect the assay at these low concentrations. The next serial dilution was at a third of this concentration.

Reference $\mathrm{IC}_{50}$ values were compared to those previously published from 96-well methodologies for the Alamar Blue assay [11-13] and a 96-well methodology for the luciferase assay [16]. A 500 cells/mL inoculum resulted in an $\mathrm{IC}_{50}$ value of $123.4 \mathrm{nM}$ for diminazene, $7.6 \mathrm{nM}$ for staurosporine (Table 1) and $3.6 \mathrm{nM}$ for pentamidine (results not shown). A reduction in the cell inoculum to 250 cells $/ \mathrm{mL}$ reduced the $\mathrm{IC}_{50}$ value of compounds slightly; diminazene 2 times and pentamidine 1.4 times, however the staurosporine $\mathrm{IC}_{50}$ value was not affected. Increasing the cell number resulted in a decrease in sensitivity for all compounds, and an increase in the variability of replicates.

\section{Optimisation of DMSO concentration}

Final DMSO concentrations from 0 to $8.3 \%$ DMSO were initially tested for a 500 cells/mL inoculum and it was found there was a decrease in the assay signal exhibited from greater than 1\% DMSO in the assay (Figure 6A). It was found that using a final concentration of $0.5 \%$ DMSO in the assay, however, resulted in a poor reproducibility across the plate, with a $Z^{\prime}$ of 0.45 (results not shown). Experiments were undertaken with a pre-dilution of DMSO before addition to the plate, using a 1:20 and 1:40 dilution before the addition of $5 \mu \mathrm{L}$ of this dilution volume to the assay volume (Figure 6B). The resulting final DMSO concentrations were $0.417 \%$ and $0.208 \%$, respectively Results were replicated for both 250 and 500 cells/

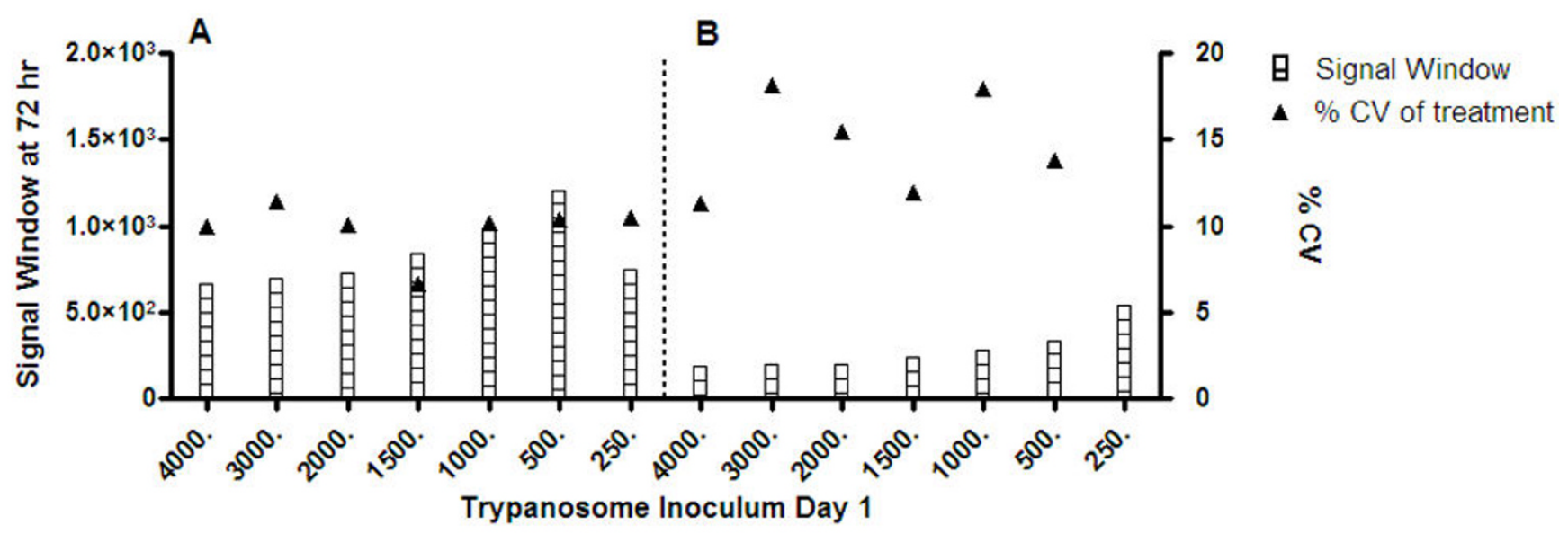

Figure 5

Signal window and \% CV of samples from varying inocula of trypanosomes following 72 hours growth and detection with the luciferase viability assay. The assay signal window and \% CV after 72 hours growth with differing trypanosome inocula were compared with both $15 \mu \mathrm{L}(\mathrm{A})$ and $10 \mu \mathrm{L}(\mathrm{B})$ of detectant. The signal window was calculated from media without a cell addition. 
Table I: Luciferase assay estimated activities over varying T.b.brucei inocula for the reference compounds staurosporine and diminazene.

\begin{tabular}{lll}
\hline Cell density $/ \mathrm{mL}$ & Staurosporine & Diminazene \\
\hline $\mathbf{2 0 0 0}$ & $13.50 \pm 8.5$ & $453.8 \pm 130.2$ \\
$\mathbf{1 5 0 0}$ & $19.90 \pm 1.3$ & $138.1 \pm 4.4$ \\
1000 & $8.73 \pm 3.2$ & $178.2 \pm 57.7$ \\
$\mathbf{5 0 0}$ & $7.60 \pm 0.6$ & $123.4 \pm 6.4$ \\
$\mathbf{2 5 0}$ & $7.96 \pm 1.2$ & $61.80 \pm 7.1$ \\
\hline
\end{tabular}

$I C_{50}$ values for each reference compound/cell inoculum concentration are expressed in \pm standard deviation, in $\mathrm{nM}$.

$\mathrm{mL}$ inocula. The Z' for detection using a final DMSO concentration of $0.417 \%$ and a 500 cells $/ \mathrm{mL}$ inoculum was 0.57 . Decreasing the cell inoculum to 250 cells $/ \mathrm{mL}$ resulted in a $Z^{\prime}$ of $-0.60 \%$, reflecting poor reproducibility for this cell concentration.

For a final DMSO concentration of $0.208 \%$, the $Z^{\prime}$ was increased to 0.65 (Figure 6B). For 250 cells $/ \mathrm{mL}$, a $0.208 \%$ DMSO concentration gave a $Z^{\prime}$ of 0.15 which consequently was not suitable for screening. The DMSO concentration may have to be diluted further to enable this cell concentration to be employed in HTS.

Comparisons were made between manual and automated additions of reagents for these dilutions. No difference in the $Z^{\prime}$ was observed between the manual and automated dispensing (results not shown).

\section{Optimisation of compound dilution medium}

Reference compounds diluted in water resulted in a decrease in sensitivity when compared to results obtained following dilution of compounds with HMI-9 medium (Table 2). Dilutions made with HMI-9 medium without FCS, compared with FCS containing medium, had a negligible effect on the estimated $\mathrm{IC}_{50}$ values excepting the staurosporine $\mathrm{IC}_{50}$, increased slightly by 2.1 times. PBS increased the $\mathrm{IC}_{50}$ values with the exception of diminazene, by a factor of 1.8 and 2.1 times for pentamidine and staurosporine respectively, in comparison to medium with no FCS.

The mean $\mathrm{IC}_{50}$ values of reference compounds $(\mathrm{n}=3)$ were estimated using the final HTS conditions. Staurosporine had an $\mathrm{IC}_{50}$ value of $1.94 \pm 0.09 \mathrm{nM}$, diminazene $60.88 \pm 27.69 \mathrm{nM}$ and pentamidine $11.91 \pm 4.86$ $\mathrm{nM}$.

\section{Discussion}

A number of assay formats have been used to screen trypanosome species including ${ }^{3} \mathrm{H}$-hypoxanthine incorporation, nuclear staining techniques, flow cytofluorometry and measurement of culture $\mathrm{pH}$ [27]. The Alamar Blue assay was developed to improve associated assay variables such as long incubations, costly reagents and poor assay reproducibility/signal [14] and the assay has been extensively reported in the literature [5,11-14]. More recently, a luminescence assay to detect intracellular ATP has been used in 96-well format $[16,17]$. Such an assay could be an alternative assay for HTS to the commonly used Alamar Blue assay. When comparing the feasibility of using these assays one point is the necessity to add Alamar Blue under sterile conditions, which may impact on potential robotic manipulations. Some HTS robotic systems may not be under sterile conditions and therefore the luciferase assay may be favoured to decrease manual work associated with
A

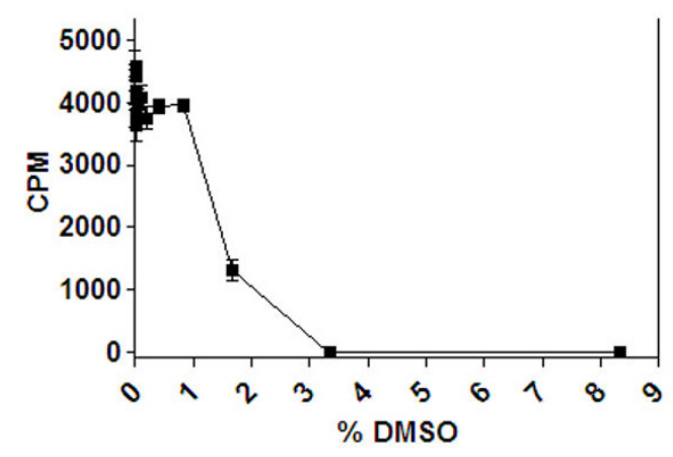

B

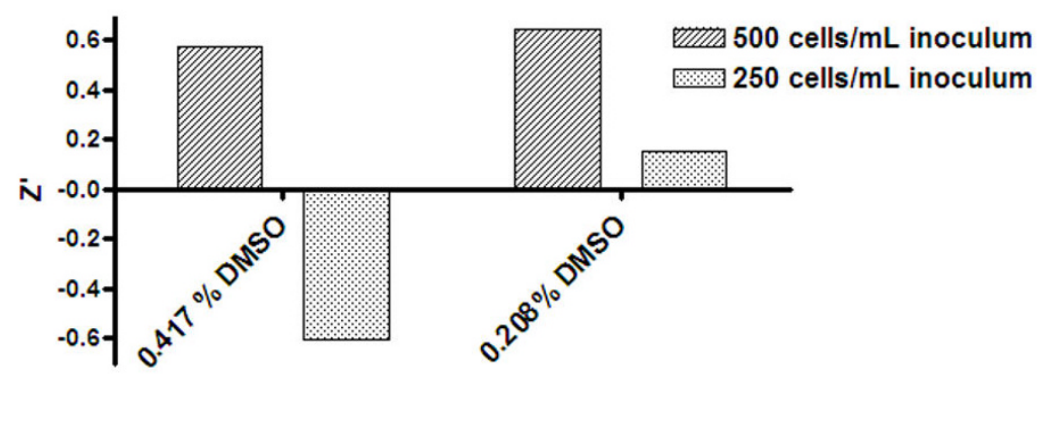

\section{Figure 6}

DMSO dose response curve for 500 cells $/ \mathrm{mL}$ inoculum; and the $Z^{\prime}$ of pre-diluted DMSO at 0.4 I $7 \%$ and $0.208 \%$ final concentration in the assay for a $\mathbf{5 0 0}$ and $\mathbf{2 5 0}$ cells $/ \mathrm{mL}$ inoculum density. (A) DMSO standard curve from 0 to 8.3\% DMSO in the luciferase assay for a $500 \mathrm{cell} / \mathrm{mL}$ inoculum (B) DMSO concentration and Z' of 500 and $250 \mathrm{~mL}$ cell inocula with a pre-dilution of DMSO to decrease the assay concentration. The $Z^{\prime}$ was estimated from a quarter of a 384 well plate. 


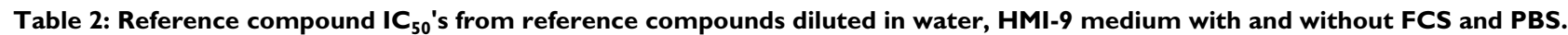

\begin{tabular}{lllll}
\hline Compound & PBS & Water & FCS & No FCS \\
\hline Pentamidine & $13.42 \pm 7.5$ & $57.78 \pm 40$ & $9.23 \pm 0.71$ & $7.56 \pm 2.8$ \\
Diminazine & $65.98 \pm 1.7$ & $140.6 \pm 79$ & $65.79 \pm 21$ & $62.46 \pm 21.3$ \\
Staurosporine & $10.99 \pm 1.3$ & $12.27 \pm 3.0$ & $2.43 \pm 0.59$ & $5.22 \pm 1.1$ \\
\hline
\end{tabular}

$I C_{50}$ values of compounds in variations of compound dilution media were determined in the luciferase assay and calculated from duplicate samples, expressed as $\pm \mathrm{SD}$, in $\mathrm{nM}$.

the end point addition. However, the luciferase assay requires plate shaking for cell lysis and not all HTS systems are capable of this step. Both assays are, however, commercially available and this allows access to these reagents for many laboratories for comparative development, dependant upon the capability of the laboratory equipment at hand.

We have described a luciferase based ATP detection assay for estimation of T.b.brucei viability in a 384-well plate for a detection of a small volume of trypanosomes $(55 \mu \mathrm{L})$ compared with previously employed 96-well protocols which utilised a sample volume of $100 \mu \mathrm{L}[16,17]$. The assay described here is reproducible, conforms to HTS standards with a $Z^{\prime}$ of 0.65 (Figure 6B), and has similar $\mathrm{IC}_{50}$ values for known T.b.brucei reference compounds as previously reported Alamar Blue assays, a luminescent viability assay (Table 3 ) and also to a recently reported Alamar Blue assay in 384-well format [15].

Variables that were explored to determine the best conditions to use in the 384-well assay included cell concentration, volume of detection agent, DMSO sensitivity and the compound diluent. The concentration of the cell inoculum to provide optimal cell growth and detection under our experimental conditions was found to be 500 cells/ $\mathrm{mL}$. For cell growth, an inoculum of 2000 cells/mL produced a maximum cell number of $3 \times 10^{6}$ cells $/ \mathrm{mL}$ following 72 hours incubation. In comparison, an inoculum of 3000 cells $/ \mathrm{mL}$ resulted in a decrease in the final cell number (Figure 4). This would be most likely attributed to the fact that the culture is in decline, with the occur-

Table 3: Reported activities for T.b.brucei reference compounds.

\begin{tabular}{llll}
\hline Compound & Reference & IC $_{\mathbf{5 0}}(\mathbf{n M})$ & Assay \\
\hline Diminazene & {$[11]$} & 90 & Alamar Blue \\
Diminazene & {$[12]$} & 500 & Alamar Blue \\
Diminazene & {$[13]$} & 990 & Alamar Blue \\
Pentamidine & {$[11]$} & 10 & Alamar Blue \\
Pentamidine & {$[13]$} & 40 & Alamar Blue \\
Staurosporine & {$[16]$} & 7 & Luciferase \\
\hline
\end{tabular}

$\mathrm{IC}_{50}$ values from various publications are listed for comparison. Assay formats include variations of the Alamar Blue viability assay and ATP detection using bioluminescence. rence of observed cell death. We have previously seen this decline in cultures exceeding over an approximated density of $3 \times 10^{6}$ cells $/ \mathrm{mL}$ [15]. This density maximum density had also previously been determined from other studies for other T.brucei bloodstream species to be $3 \times$ $10^{6} \mathrm{cells} / \mathrm{mL}$ [28]. The doubling time reported here was calculated to be on average 6.8 hours which is also similar to previously reported doubling times for other $T$. brucei bloodstream species in HMI-9 medium [28].

A cell inoculum of 2000 cells/mL produced the maximum cell number (Figure 4 , just over $3 \times 10^{6}$ cells $/ \mathrm{mL}$ ) and this cell concentration was synonymous with a slight decrease in the luciferase signal in comparison to 1 or $2 \times 10^{6} \mathrm{cells} /$ $\mathrm{mL}$ with cells directly transferred from a flask (Figures 2 and 3 ). The signal was also reduced in comparison to cell inocula of 1000 and 500 cells/mL grown in a plate (Figure 5). As cell number was at maximum from cells grown from an inoculum of 2000 cells $/ \mathrm{mL}$, this signal decrease could be a function of cells reaching a stationary phase of growth and therefore the ATP production decreasing. This phase related decline in ATP production has been observed in other cell lines [29-31] and is synonymous with a high cell density in fibroblast cell culture [32]. Cell density has been shown to regulate trypanosome number in infections by differentiation induced by stumpy induction factor at high concentrations [33], and it could be suggested that other metabolites may be produced at higher cell densities which effect cultures in monomorphic forms. As cells detected directly from a flask culture exhibited a decrease in CPM at $3 \times 10^{6} \mathrm{cells} / \mathrm{mL}$ in comparison to $2 \times 10^{6}$ cells $/ \mathrm{mL}$ (diluted from a $3 \times 10^{6}$ cells/ $\mathrm{mL}$ culture density; Figure 2), there may have also been interference from ATPases released from the maximum concentration of lysed cells, reducing the signal. This signal interference was not a function of the maximum ATP that could be detected in the well, as this signal plateaued at much higher CPM (Figure 1).

Titrating down to lower densities of trypanosomes revealed a linear relationship between cell number and signal between $1 \times 10^{3}$ to $1 \times 10^{6}$ cells $/ \mathrm{mL}$ trypanosomes from cells directly transferred from a flask grown culture (Figure 3B). Mackey and colleagues [16] found a linear relationship between trypanosome concentration and 
luciferase signal to $6 \times 10^{4}$ cells/well. As the inoculum for this assay was $1 \times 10^{5} \mathrm{cells} / \mathrm{mL}$, with a doubling time estimated at 6.8 hours for example, the final assay concentration of cells following 48 hours incubation would have reached over maximum, at $3 \times 10^{6}$ cells $/ \mathrm{mL}$, or $3 \times 10^{5}$ cells/well, so it can not be determined if a similar effect was seen in this assay with the concentrations examined for a linear trend.

With plate inoculated cultures, the cell number that produced the greatest signal window was 500 cells/mL (Figure 5). This inoculum resulted in approximately $1.7 \times 10^{6}$ cells/mL following 72 hours growth in plate (Figure 4). This suggested a slightly faster doubling time in the plate, as forecast by the doubling time equation this cell inoculum should be under $1 \times 10^{6}$ cells $/ \mathrm{mL}$. However, at this low cell inoculum, there is not a linear trend in growth as we have previously observed [15], and therefore the doubling time would not be expected to be constant. Relating this concentration to the linearity of cell number versus CPM from direct cell transfer, suggested that this cell concentration was slightly above the linear range of the assay, which was at a maximum of $1 \times 10^{6}$ cells $/ \mathrm{mL}$ (Figure 3B). Taking this into consideration, it was determined that reduction of the cell number to less than $1 \times 10^{6}$ cells $/ \mathrm{mL}$ final in the assay, or an inoculum of 250 cells $/ \mathrm{mL}$ of trypanosomes, could be applied for HTS. The DMSO tolerability for 250 compared with 500 cells $/ \mathrm{mL}$ was explored at both a $0.417 \%$ and $0.208 \%$ final DMSO concentration. The assay incorporating a 500 cells/mL inoculum at $0.208 \%$ DMSO resulted in the least variability, reflected in a $Z^{\prime}$ of 0.64 (Figure 6B). However, a 250 cells/ $\mathrm{mL}$ inoculum resulted in a $\mathrm{Z}^{\prime}$ of less than 0.5 for both DMSO concentrations and therefore was not acceptable for HTS application. The DMSO concentration would need to be further reduced to allow this inoculum to be applied, which would bring about potential library concerns as samples would have to be diluted further before screening, therefore potentially reducing the sensitivity of the assay at this cell density. Mackey and colleagues [16] employed a DMSO concentration of $1 \%$ at the stage of cell addition in a 96-well luciferase assay. The 384-well assay would have an estimated cell number at the time of addition of DMSO of around 345 cells/well (estimating a doubling time of 6.8 hours) in comparison to an estimated 1 $\times 10^{4}$ cells/well in the 96 -well format which could explain the differences in the necessity for a lower DMSO requirement for 384-well screening using the HTS conditions as outlined here.

Table 3 shows reference compound activities for both reported Alamar Blue assays and a reported luciferase based ATP detection assay in 96-well format. We found that a $500 \mathrm{cell} / \mathrm{mL}$ inoculum resulted in $\mathrm{IC}_{50}$ concentrations that were comparable to those found in the litera- ture from dosing compounds with differing trypanosome inocula. From Table 1, increasing the cell density decreased the sensitivity to both diminazene and staurosporine, when making comparisons of inoculums of 500 cells/mL with 2000 cells/mL. There was a 3.7 and 1.8 times reduction in the $\mathrm{IC}_{50}$ values of diminazene and staurosporine, respectively. A 3.3 times reduction in activity was also revealed for pentamidine (results not shown). It is not possible to directly compare the Alamar Blue assay formats to the assay reported here due to the detection reagents used, incubation time, media differences and cell inoculation variables between assays. However, a similar sensitivity was observed with results obtained by Lanteri and collegues [11], with an $\mathrm{IC}_{50}$ value for pentamidine of $10 \mathrm{nM}$ and diminazene $90 \mathrm{nM}$ reported, compared to those observed, pentamidine $11.91 \mathrm{nM}$ and diminazene $60.88 \mathrm{nM}$. The sensitivity to staurosporine observed using a 500 cells $/ \mathrm{mL}$ inoculum (an $\mathrm{IC}_{50}$ of $1.94 \mathrm{nM}$ ) was comparable to the 96-well format previously reported [16] $\left(\mathrm{IC}_{50}\right.$ of $\left.7 \mathrm{nM}\right)$. As there may have been some interference with a higher cell density used by these authors in comparison to the protocol reported here, and as staurosporine has a high Hill Slope ( 3 over all cell doses), further experiments would further determine sensitivities between these assay formats with other known antitrypanosomals.

Importantly, the assay inoculum employed in the HTS assay developed fits HTS statistical criteria The assay is within the linear range of the detection of the reader (Figure 1), and approximately $0.7 \times 10^{6}$ cells $/ \mathrm{mL}$ from the linear range of detection of cells estimated in the assay system (Figure 3B). The assay at the defined cell inoculum of 500 cells/mL has sensitivity to known compounds similar to published reference compound activity in other assay formats (Table 3).

The potential diluent used for the addition of compounds and/or controls to the assay was explored, as pre-dilution of DMSO, due to DMSO sensitivity, was necessary. During a HTS campaign it is not uncommon for the screening library to be pre-diluted into the assay plate prior to HTS commencing. Exclusion of FCS from such a dilution medium was considered as this may reduce the risk of certain contaminating microorganisms [34], considering that there is a brief exposure of plates to the atmosphere whilst the dilution is carried out. FCS has also been found to influence cellular toxicity due to components binding to inhibitor compounds [35] and therefore dilutions and storage in a medium with FCS may potentially influence compound activity. Thus, FCS was not included in the diluents used here. The use of water as a diluent increased the $\mathrm{IC}_{50}$ value of the reference compounds by $7.6,2.3$ and 2.4 times, respectively for pentamidine, diminazene and staurosporine in comparison to medium without FCS 
(Table 2). There was also a decrease in the cell number by 1.5 times with the water addition (results not shown). This could have been as a result of a slight difference in the buffering capacity of the system or an osmotic effect of water on the cells, potentially causing cell lysis. For the optimal 384-well assay performance, HMI-9 medium with exclusion of the FCS component was the diluent of choice, as it did not significantly change the $\mathrm{IC}_{50}$ value of the reference compounds.

\section{Conclusion}

We have reported here the successful development and optimisation of a luciferase based cell viability assay in 384-well format for use in HTS of T.b.brucei BS427, which exhibits benefits compared with previously published assay methodologies. Notably the assay is reproducible, fits statistical parameters, with a similar sensitivity to known drugs in comparison with previously published results and is cheaper than the currently used 96-well assay format for HTS. The assay described here is approximately three times less expensive per well than the 96well luciferase assay currently reported in the literature. Importantly, the assay is biologically relevant, and has been shown statistically to perform well, adhering to the $Z^{\prime}$ criteria imposed (cut off of 0.5 , but closest to 1 as possible). Additions of assay reagents and cells were made with automated liquid handlers, allowing for rapid additions for HTS and handling of a large plate numbers.

To our knowledge this is the first report of a 384-well cell viability assay for T.b.brucei utilising cellular ATP estimation, with a luciferase based detection agent. A future considerations is the comparison of the luciferase based 384well assay to the Alamar Blue based 384 well assay [15] for HTS application with a larger panel of compounds.

\section{Competing interests}

The authors declare that they have no competing interests.

\section{Authors' contributions}

MLS carried out the experimental work and drafted the manuscript. MLS participated in the design of the study and performed data analysis. VMA conceived the study, participated in its design and coordination and contributed to the manuscript preparation. All authors read and approved the final manuscript.

\section{Acknowledgements}

This study was supported by funding from the Drugs for Neglected Diseases Initiative (DNDi) and we would like to thank them for their financial support. The authors wish to thank Dr Achim Schnaufer, (Institute of Cell Biology, University of Edinburgh, UK) who whilst at the Seattle Biomedical Research Institute, kindly supplied the trypanosome cell stock used throughout this study and Gillian Fisher for technical assistance.

\section{References}

I. Human African trypanosomiasis (sleeping sickness): epidemiological update. Wkly Epidemiol Rec 2006, 8 I:7I-80.

2. Pepin J, Milord F: The treatment of human African trypanosomiasis. Adv Parasitol 1994, 33: I-47.

3. Bales JD Jr, Harrison SM, Mbwabi DL, Schecter PJ: Treatment of arsenical refractory Rhodesian sleeping sickness in Kenya. Ann Trop Med Parasitol I 989, 83(SuppI I): I I I-I I4.

4. Burri C, Keiser J: Pharmacokinetic investigations in patients from northern Angola refractory to melarsoprol treatment. Trop Med Int Health 200I, 6:4I 2-420.

5. Matovu E, Stewart ML, Geiser F, Brun R, Maser P, Wallace LJ, Burchmore RJ, Enyaru JC, Barrett MP, Kaminsky R, Seebeck T, de Koning HP: Mechanisms of arsenical and diamidine uptake and resistance in Trypanosoma brucei. Eukaryot Cell 2003, 2:1003-1008.

6. Mpia B, Pepin J: Combination of eflornithine and melarsoprol for melarsoprol-resistant Gambian trypanosomiasis. Trop Med Int Health 2002, 7:775-779.

7. Pink R, Hudson A, Mouries MA, Bendig M: Opportunities and challenges in antiparasitic drug discovery. Nat Rev Drug Discov 2005, 4:727-740.

8. Pecoul B: New drugs for neglected diseases: from pipeline to patients. PLoS Med 2004, I:e6.

9. Holloway GA, Charman WN, Fairlamb AH, Brun R, Kaiser M, Kostewicz E, Novello PM, Parisot JP, Richardson J, Street IP, Watson KG, Baell JB: Trypanothione reductase high-throughput screening campaign identifies novel classes of inhibitors with antiparasitic activity. Antimicrob Agents Chemother 2009, 53:2824-2833.

10. Martyn DC, Jones DC, Fairlamb $A H$, Clardy J: High-throughput screening affords novel and selective trypanothione reductase inhibitors with anti-trypanosomal activity. Bioorg Med Chem Lett 2007, I 7: I280-1283.

II. Lanteri CA, Stewart ML, Brock JM, Alibu VP, Meshnick SR, Tidwell RR, Barrett MP: Roles for the Trypanosoma brucei P2 transporter in DB75 uptake and resistance. Mol Pharmacol 2006, 70: $1585-1592$.

12. Merschjohann K, Steverding D: In vitro growth inhibition of bloodstream forms of Trypanosoma brucei and Trypanosoma congolense by iron chelators. Kinetoplastid Biol Dis 2006, 5:3.

13. Stewart ML, Boussard C, Brun R, Gilbert IH, Barrett MP: Interaction of monobenzamidine-linked trypanocides with the Trypanosoma brucei P2 aminopurine transporter. Antimicrob Agents Chemother 2005, 49:5169-5I7I.

14. Raz B, Iten M, Grether-Buhler Y, Kaminsky R, Brun R: The Alamar Blue assay to determine drug sensitivity of African trypanosomes (T.b.rhodesiense and T.b.gambiense) in vitro. Acta Trop 1997, 68:139-147.

15. Sykes ML, Avery VM: Development of an Alamar Blue viability assay in 384-well format for high throughput whole cell screening of Trypanosoma brucei brucei bloodstream form strain 427. Am J Trop Med Hyg 2009, 8I:665-674.

16. Mackey ZB, Baca AM, Mallari JP, Apsel B, Shelat A, Hansell EJ, Chiang PK, Wolff B, Guy KR, Williams J, McKerrow JH: Discovery of trypanocidal compounds by whole cell HTS of Trypanosoma brucei. Chem Biol Drug Des 2006, 67:355-363.

17. Mackey ZB, O'Brien TC, Greenbaum DC, Blank RB, McKerrow JH: A cathepsin $B$-like protease is required for host protein degradation in Trypanosoma brucei. J Biol Chem 2004, 279:48426-48433.

18. Kinabo LD: Pharmacology of existing drugs for animal trypanosomiasis. Acta Trop 1993, 54:169-183.

19. Rifkin MR: Identification of the trypanocidal factor in normal human serum: high density lipoprotein. Proc Natl Acad Sci USA 1978, 75:3450-3454.

20. Zhang JH, Chung TD, Oldenburg KR: A Simple Statistical Parameter for Use in Evaluation and Validation of High Throughput Screening Assays. J Biomol Screen 1999, 4:67-73.

21. Iversen PW, Eastwood BJ, Sittampalam GS, Cox KL: A comparison of assay performance measures in screening assays: signal window, Z' factor, and assay variability ratio. J Biomol Screen 2006, I I :247-252.

22. Zhang H, Nimmer P, Rosenberg SH, Ng SC, Joseph M: Development of a high-throughput fluorescence polarization assay for Bcl-x(L). Anal Biochem 2002, 307:70-75. 
23. Sui $Y, W u$ Z: Alternative statistical parameter for highthroughput screening assay quality assessment. J Biomol Screen 2007, I 2:229-234.

24. Braga MV, de Souza W: Effects of protein kinase and phosphatidylinositol-3 kinase inhibitors on growth and ultrastructure of Trypanosoma cruzi. FEMS Microbiol Lett 2006, 256:209-2। 6 .

25. Arnoult D, Akarid K, Grodet A, Petit PX, Estaquier J, Ameisen JC: On the evolution of programmed cell death: apoptosis of the unicellular eukaryote Leishmania major involves cysteine proteinase activation and mitochondrion permeabilization. Cell Death Differ 2002, 9:65-8I.

26. Hirumi $\mathrm{H}$, Hirumi K: Continuous cultivation of Trypanosoma brucei blood stream forms in a medium containing a low concentration of serum protein without feeder cell layers. J Parasitol 1989, 75:985-989.

27. Kaminsky R, Brun R: In vitro assays to determine drug sensitivities of African trypanosomes: a review. Acta Trop 1993, 54:279-289.

28. Graham SV, Wymer B, Barry JD: Activity of a trypanosome metacyclic variant surface glycoprotein gene promoter is dependent upon life cycle stage and chromosomal context. Mol Cell Biol 1998, I 8: I I37-I I 46.

29. Haddix PL, Jones S, Patel P, Burnham S, Knights K, Powell JN, LaForm $A$ : Kinetic analysis of growth rate, ATP, and pigmentation suggests an energy-spilling function for the pigment prodigiosin of Serratia marcescens. J Bacteriol 2008, 190:7453-7463.

30. Fiorani M, Cantoni O, Piccoli G, Biagiarelli B, Stocchi V: Cell densitydependent regulation of ATP levels during the growth cycle of cultured Chinese hamster ovary cells. Biochem Mol Biol Int 1994, 32:251-258.

31. Sonderhoff SA, Kilburn DG, Piret JM: Analysis of mammalian viable cell biomass based on cellular ATP. Biotechnol Bioeng 1992, 39:859-864.

32. Vlodavsky I, Inbar M, Sachs L: Membrane changes and adenosine triphosphate content in normal and malignant transformed cells. Proc Natl Acad Sci USA 1973, 70: I780- 1784.

33. Vassella E, Reuner B, Yutzy B, Boshart M: Differentiation of African trypanosomes is controlled by a density sensing mechanism which signals cell cycle arrest via the cAMP pathway. J Cell Sci 1997, I I 0(Pt 2I):266I-267I.

34. Even MS, Sandusky CB, Barnard ND: Serum-free hybridoma culture: ethical, scientific and safety considerations. Trends Biotechnol 2006, 24: 105-108.

35. Gulden M, Morchel S, Seibert H: Serum albumin binding at cytotoxic concentrations of chemicals as determined with a cell proliferation assay. Toxicol Lett 2003, 137:159-168.
Publish with Biomed Central and every scientist can read your work free of charge

"BioMed Central will be the most significant development for disseminating the results of biomedical research in our lifetime. "

Sir Paul Nurse, Cancer Research UK

Your research papers will be:

- available free of charge to the entire biomedical community

- peer reviewed and published immediately upon acceptance

- cited in PubMed and archived on PubMed Central

- yours - you keep the copyright

Submit your manuscript here:

http://www.biomedcentral.com/info/publishing_adv.asp
BioMedcentral 